\title{
Thermogravimetric analysis of aluminised E-glass fibre reinforced unsaturated polyester composites
}

\author{
J.M. Ferreira ${ }^{\mathrm{a}, *}$, O.A.Z. Errajhi ${ }^{\mathrm{b}}$, M.O.W. Richardson ${ }^{\mathrm{b}}$ \\ a ICEMS, Dsabbaticalepartment of Mechanical Engineering, University of Coimbra, Rua Luis Reis Santos 3030-788, Coimbra, Portugal \\ ${ }^{\mathrm{b}}$ Advanced Composite Research Group, Department of Mechanical and Design Engineering, University of Portsmouth Anglesea Road, \\ Portsmouth, Hampshire PO1 3DJ, UK
}

Received 5 June 2006; accepted 22 July 2006

\begin{abstract}
Novel aluminised E-glass fibre reinforced unsaturated polyester composites, originally formulated for enhanced thermal and electrical shielding properties were evaluated in terms of their thermal performance. The thermal degradation of these specimens was analysed using a thermogravimetric analyser (TGA). The samples were heated from ambient temperature to $500{ }^{\circ} \mathrm{C}$ at a heating rate of $20^{\circ} \mathrm{C} / \mathrm{min}$. All specimens were decomposed under dry nitrogen $\left(\mathrm{N}_{2}\right)$ at a flow rate of $40 \mathrm{ml} / \mathrm{min}$ to yield gases and solid char. Aluminised E-glass composites were compared alongside the unmetallised E-glass and unreinforced composite. The major weight loss occurred between 200 and $400{ }^{\circ} \mathrm{C}$. The unreinforced polyester had a maximum weight loss, $1.25 \% /{ }^{\circ} \mathrm{C}$, occurring at $360^{\circ} \mathrm{C}$. For the aluminised and unmetallised E-glass composites, the maximum rate of weight loss was 0.34 and $0.55 \% /{ }^{\circ} \mathrm{C}$, respectively. Experimental results show the degradation of the aluminised E-glass composites obtained from TGA tests is higher compared to those of unmetallised E-glass fibre and unreinforced polyester composite. This improvement is correlated to the aluminium coating.
\end{abstract}

(C) 2006 Elsevier Ltd. All rights reserved.

Keywords: Aluminised fibre; Thermogravimetric analysis; Fibre degradation

\section{Introduction}

Composite materials based on aluminium have been widely studied for decades. Some of these materials have found commercial applications, mainly in aerospace and automotive industries. Glass fibres account for around $90 \%$ of the reinforcement used in structural reinforcement plastic applications [1].

\footnotetext{
*Corresponding author. Tel.: + 351239790700 ; fax: +351239790701 .

E-mail address: martins.ferreira@dem.uc.pt (J.M. Ferreira).
}

For some years, aluminised glass fibre has been used in counter measure technology. Aircraft release such fibres in order to confuse and divert approaching enemy missiles. Until now, aluminised E-glass fibres have only been used in military applications. The main potential advantages of producing modified composites from the same type of fibre are to modify or improve mechanical and physical properties. Aluminised glass fibre is expected to significantly modify thermal and electric characteristics by virtue of an increase in thermal conductivity [1,2].

Thermal analysis includes a group of analytical methods in which the properties of a substance or a 
polymeric material are measured as a function of temperature. Thus, dynamic thermogravimetry involves a physical measurement in which the weight loss is recorded as a function of the temperature while the substance is subjected to a controlled temperature programme.

In polymer production, it is very important to determine the thermal stability of the polymeric material because this gives the temperature range over which the material can be used without degradation. The degradation of condensation polymers can occur by random decomposition or at reactive sites in the polymeric chain, depending on the nature of the polymeric material, while depolymerisation reactions with monomer formation are characteristic of vinylic polymer structure. Thus, the principal degradation reactions will depend on the polymer structure and the heating conditions [3]. In the degradation of polyesters, intermolecular ester exchange and $\beta$ - $\mathrm{CH}$ hydrogen transfer are the two processes mainly responsible for the primary steps of the thermal decomposition. However, in polyesters derived from aliphatic dicarboxylic acids and diphenols, and in totally aromatic polyesters, the ester exchange process prevails in the primary thermal cleavage $[3,4]$.

Thermogravimetric analysis (TGA) is one of the major thermal analysis techniques and has found a broad application in the field of characterisation of polymeric materials. For some studies, such as investigation of degradation mechanisms, it is, however, not sufficient since the thermoanalytical curves yield only summarised information about the process, and cannot differentiate between partial reactions. Further information may be obtained from an analysis of first and subsequent derivatives, but it is essentially not possible to take a deeper look into the degradation mechanism. A valuable contribution is offered by a detailed kinetic analysis, with the first step of model-free determination of the activation energy [3-5].

Whilst there has been extensive work on glass/ polyester systems, until now work on polymer composite materials reinforced by aluminised E-glass fibre has not been reported [6-10]. In order to assess possible applications of this new type of composite, the expected advantages must be experimentally confirmed by mechanical and physical property characterisation in order to make comparisons with common glass fibre composites [11-14]. The aim of this current study was therefore to fabricate composite samples using aluminised
E-glass fibre as the reinforcement and unsaturated polyester as the matrix and to evaluate their thermal properties. Experimental procedures of the aluminised E-glass fibre composite can be found elsewhere [1].

\section{Test method}

TGA was carried out using a TGA Q 50 V6.1 Build 181 TGA. The TGA curves were obtained under dry nitrogen $\left(\mathrm{N}_{2}\right)$ atmosphere at a flow rate of $40 \mathrm{ml} / \mathrm{min}$ and a scanning rate of $20^{\circ} \mathrm{C} / \mathrm{min}$.

\section{Results and discussion}

The thermal degradation of aluminised E-glass fibre was studied and experimentally compared to unmetallised E-glass fibre and unreinforced polyester. The 1st derivative (DTG) and the thermograms of aluminised E-glass, unmetallised E-glass and unreinforced polyester are shown in Figs. 1 and 2, respectively. The summary of the important characteristic temperature obtained from the thermogram and DTG are listed in Table 1.

It is evident from Fig. 1 that for the unreinforced polyester there are more than one peak occurring between 210 and $350^{\circ} \mathrm{C}$ in the DTG curve, which shows that the degradation is a two-stage process. The first process started just before $200{ }^{\circ} \mathrm{C}$ and reached its maximum rate of $0.10 \% /{ }^{\circ} \mathrm{C}$ at $210{ }^{\circ} \mathrm{C}$. The second weight loss process developed later and showed a higher maximum rate of decomposition $1.25 \% /{ }^{\circ} \mathrm{C}$ at approximately $360{ }^{\circ} \mathrm{C}$. The amount of char left for this specimen at $500{ }^{\circ} \mathrm{C}$ was approximately $9 \%$.

For the unmetallised E-glass specimen, the weight loss began at $180^{\circ} \mathrm{C}$, and then three peaks from DTG of weight loss process were observed at approximately 210,340 and $470{ }^{\circ} \mathrm{C}$, with the one in the middle having the maximum rate of weight loss of $0.55 \% /{ }^{\circ} \mathrm{C}$. The residue of $58 \%$ was found at $500{ }^{\circ} \mathrm{C}$.

In the case of aluminised E-glass specimen, it was also observed that there are two peaks of weight loss. The specimen started to degrade after about $210{ }^{\circ} \mathrm{C}$. The specimen then reached a maximum rate of $0.24 \% /{ }^{\circ} \mathrm{C}$ at $380{ }^{\circ} \mathrm{C}$ and, finally, the residue yield was $74 \%$ at $500{ }^{\circ} \mathrm{C}$. This was the highest residue left by the three materials. 


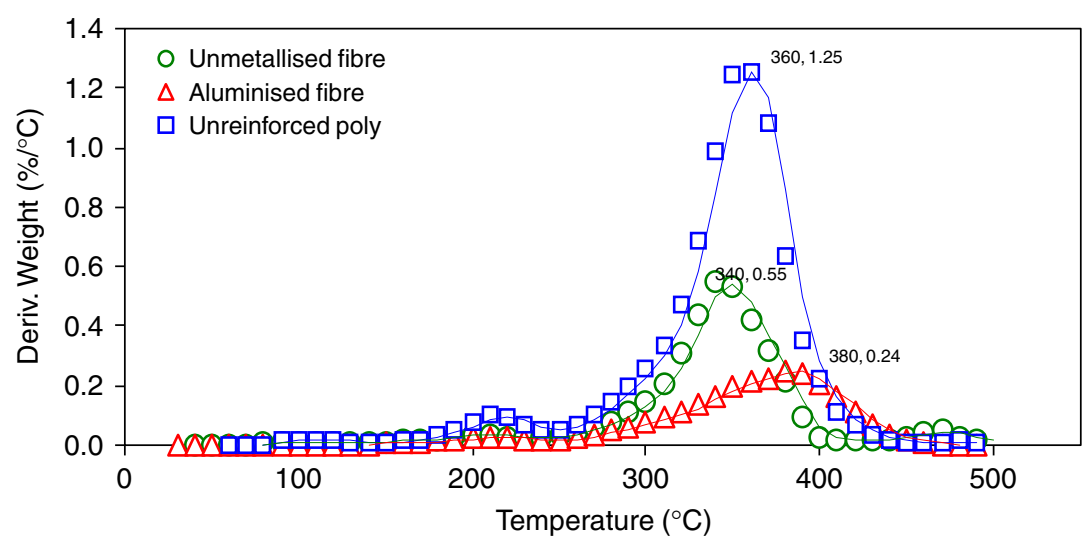

Fig. 1. Derivative Themograms.

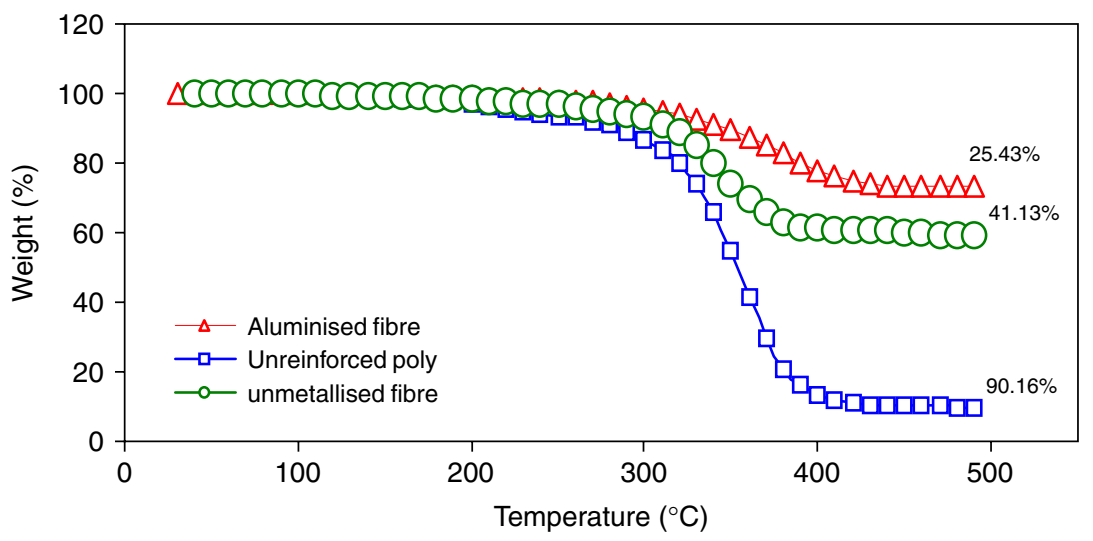

Fig. 2. Thermograms traces.

Table 1

The characteristic temperatures at elevated weight loss

\begin{tabular}{|c|c|c|c|c|c|c|}
\hline Specimens & $T_{\text {Onset }}\left({ }^{\circ} \mathrm{C}\right)$ & $T_{10 \%}\left({ }^{\circ} \mathrm{C}\right)$ & $T_{25 \%}\left({ }^{\circ} \mathrm{C}\right)$ & $T_{50 \%}\left({ }^{\circ} \mathrm{C}\right)$ & $T_{\text {End }}\left({ }^{\circ} \mathrm{C}\right)$ & $M_{\text {Resid }}(\%)$ \\
\hline Unreinforced polyester & 204.7 & 285.5 & 328.7 & 353.6 & 384.4 & 9.83 \\
\hline Unmetallised E-glass & 239.9 & 315 & 348.9 & - & 374.0 & 58.87 \\
\hline Aluminised E-glass & 282.4 & 336 & 440.4 & - & 380.2 & 74.58 \\
\hline
\end{tabular}

\section{Conclusions}

The thermal degradation of an aluminised E-glass fibre reinforced unsaturated polyester composite has been successfully studied and experimentally compared to unreinforced polyester and unmetallised E-glass composite.

The char yield of the aluminised E-glass fibre composite was found to be higher than that of unmetallised E-glass fibre composite by approximately $26 \%$, and $658 \%$ higher than the unrein- forced polyester. The reason is that the presence of the aluminium coating enhances the formation of char and hinders diffusion of volatile decomposition within the composite.

\section{Acknowledgements}

The authors would like to thank Chemring ple for supplying the aluminised and unmetallised fibres. 


\section{References}

[1] O.A.Z. Errajhi, M.O.W. Richardson, Z.Y. Zhang. 2004. Impact resistance and damage characteristics of aluminised E-glass fibre reinforced unsaturated polyester composite. The polymetric composite institute of South Africa (PCISA), pp. $453-460$.

[2] O.A.Z. Errajhi, M.O.W. Richardson, H.N. Dhakal, J.R.F. Osborne, Characteristics of water absorption of aluminised E-glass fibre reinforced unsaturated polyester composite, Compos. Struct. 71 (3-4) (2005) 333-336.

[3] L. Tagle, F.R. Hand Diaz, Thermogravimetric analysis of polyester derived from terephthalic, tetrachloroterephthalic and related diacids with biphenol A, J. Thermchim. Acta 200 (1992) 281-291.

[4] K. Pielichowski, I. Hamerton, TGA/FTi.r. Studies on the thermal stability of poly (vinyl chloride) blends with a novel colourant and stabilizer: 3-(2,4-dichlorophenylazo)-9-(2,3epoxypropane) carbazole, J. Polym. 39 (1998) 241-244.

[5] F. Gong, M. Feng, C. Zhao, S. Zhang, M. Yang, Thermal properties of poly (vinyl chloride)/montmorillonite nanocomposites, J. Polym. Degrad. Stabil. (2004) 289-294.

[6] T.-W. Shyr, Y.-H. Pan, Impact resistance and damage characteristics of composite laminates, Compos. Struct. 62 (2) (2003) 193-203.
[7] A.J. Lesser, Effect of resin cross-link density on the impact damage resistance of laminated composites, Polym. Compos. 18 (1997) 16-27.

[8] S. Abrate, Impact-induced delamination, a view of bending stiffness mismatching, J. Compos. Mater. 22 (1988) 674-691.

[9] H.D. Rozman, Y.S. Yeo, G.S. Tay, A. Abubakar, The mechanical and physical properties of polyurethane composites based on rice husk and polyethylene glycol, J. Polym. Test. 22 (2003) 617-623.

[10] S. Bouzid, A. Nyoungue, Z. Azari, N. Bouaouadja, G. Pluvinage, Fracture criterion for glass under impact loading, Int. J. Impact Eng. 25 (9) (2001) 831-845.

[11] K.H.G. Ashbee, Fundamental Principles of Fibre Reinforced Composites Technomic, second ed., Lancaster, PA, 1993. p. 424.

[12] WWWsite (Osha Technical Manual) accessed July 2002 from: 〈http://www.osha-slc.gov $\rangle$.

[13] P. Forquin, L. Tran, P.-F. Louvigné, L. Rota, F. Hild, Effect of aluminum reinforcement on the dynamic fragmentation of SiC ceramics, J. Int. Impact Eng. 28 (2003) 1061-1076.

[14] B.A. Roeder, C.T. Sun, Dynamic penetration of alumina/ aluminum laminates: experiments and modeling, Int. J. Impact Eng. 25 (2) (2001) 169-185. 